\title{
Direct Evidence for TP53 Involvement of TP53 in Proliferation, Migration, and Invasion of Gastric Carcinoma Cells
}

\author{
Ying $\mathrm{Li}^{1}$, Shaojun Liu ${ }^{2 *}$, Pei Zhang ${ }^{3}$ \\ ${ }^{1}$ Department of Endoscopy Center, Shaanxi Provincial People's Hospital, \\ Xi'an, Shaanxi 710068, P.R. China; \\ ${ }^{2}$ Department of Digestion Medicine, The Third Affiliated Hospital of Xiangya \\ School of Medicine, Central South University, Changsha, Hunan 410078, P.R. \\ China; \\ ${ }^{3}$ Department of Radiation Oncology, University of Maryland School of \\ Medicine, Baltimore, MD 21221, USA.
}

*Corresponding Author: Shaojun Liu, Email: liushaojuncs123@126. com.

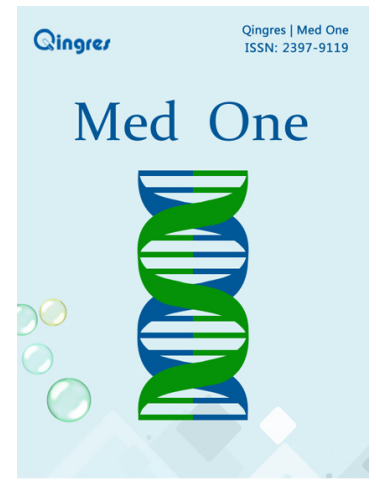

http://mo.qingres.com

\section{GOPEN ACCESS}

DOI: 10.20900/mo.20160004

Received: November 13, 2015

Accepted: January 22, 2016

Published: February 25, 2016

Copyright: ๑2016 Cain et al. This is an open access article distributed under the terms of the Creative Commons Attribution License, which permits unrestricted use, distribution, and reproduction in any medium, provided the original author and source are credited.

\begin{abstract}
Background: Abnormal p53 expression has been observed in gastric carcinoma cells. The question of whether p53 could become a target for gastric carcinoma biological therapy has not yet been determined.

Methods: TP53 was silenced by siRNA but overexpressed by vector. RT-PCR measured mRNA expression. Western blot measured protein expression. The CCK-8 method was used to analyze cell proliferation. Cell invasion and migration were analyzed, by a Transwell champer and wound healing assay, respectively.

Results: TP53 siRNA significantly silenced TP53 expression and pEGFP-TP53 vector overexpressed p53 protein. Silencing TP53 expression significantly increased cell proliferation, invasion, and migration in BGC-823 cells. In contrast, p53 overexpression significantly inhibited cell proliferation, invasion, and migration in BGC823 cells.
\end{abstract}

Conclusion: p53 overexpression may prove a useful strategy for targeted inhibition of gastric carcinoma cell growth and metastasis.

Key Words: TP53; Gastric carcinoma cell; Proliferation; Migration; Invasion 


\section{INTRODUCTION}

Gastric cancer is one of the most common digestive tract malignant tumors of the digestive tract and it ranks second, in terms of mortality, of all cancers ${ }^{[1-3]}$. Technological advances in medical imaging technologies and therapeutic advances in chemoradiotherapy, biological target therapy, and cellular immunotherapy have improved gastric carcinoma prognosis. However, it remains poor, which reflects the currently poor understanding of its pathogenic mechanisms ${ }^{[4,5]}$.

Gastric cancer is a multifactorial disease. Oncogene overexpression and tumor suppressor genes lack of expression are the primary molecular mechanisms involved in tumor growth, therapeutic resistance, and gastric cancer metastasis. Some genes, such as HER-2, VEGFR-2, EGFR, VEGF-A, mTOR, and c-MET/HGF, overexpress has been widely reported in gastric cancer patients and a targeted inhibition of these genes is currently being used as treatment options for gastric cancer ${ }^{[6]}$. Tumor suppressor genes, such as CDKN2A/p16, CDH1/E-cadherin, RUNX3, and MLH1, are often reported to be inactivated by promoter methylation, mutations, or chromosomal losses ${ }^{[7]}$. Genomic aberrations in TP53, PIK3CA, ErbB2, ErbB3, ARID1A and KRAS gene are frequently encountered in gastric cancer ${ }^{[8]}$.

TP53 gene mutation is one of the most common anomalies in human cancer. It leads to the loss of TP53 gene expression and p53 functions [9]. TP53 gene mutations are observed in 50$77 \%$ of all advanced gastric cancers ${ }^{[10,11]}$. TP53 gene expression downregulation can significantly enhance cell proliferation, migration, and gastric cancer cell invasion ${ }^{[12]}$. The effects of the $p 53$ protein on gastric cancer cell malignancy are rarely validated by a direct silencing, or an artificially expression, of the p53 protein in gastric carcinoma cell lines.

This study investigated the roles of $p 53$ in the proliferation, invasion, and migration of gastric cancer cells by silencing, and overexpressing, p53 expression in gastric carcinoma BGC-823 cells.

\subsection{Materials}

A gastric carcinoma BGC-823 cell line was purchased from the Sunbio Company (Anyang, South Korea). RPMI 1640, and fetal bovine serum, were purchased from Gibco Company (Langley, OK, USA). Transwell chamber and Martrigel were both purchased from BD Bioscience Company (Franklin Lakes, NJ, USA). A lipidosome cell transfection kit was purchased from Invitrogen (Grand Island, NY, USA). Anti-P53 and anti- $\beta$-actin antibodies were purchased from Xinlebio (Shanghai, China). A CCK8 detection kit was purchased from the Beyotime Institute (Shanghai, China). Trizol reagents and a cDNA synthesis kit were purchased from TAKARA (kusatsu, Shiga, Japan). The restriction enzyme and T4 DNA ligase were purchased from NEB (Beijing, China). The plasmid extraction kit was purchased from Omega Bio-tek, Inc (Norcross, GA, USA). The cell protein extraction kit was purchased from Thermo Scientific Company (Waltham, MA, USA).

\subsection{SiRNA design and vector construction}

The TP53 siRNA sequence was designed using a publically available online software (www.qiagen. com/siRNA). Complementary siRNA sequences were synthesized and made ready for use by Invitrogen. The TP53 gene was cloned into the pEGFP-N1 vector. cDNA from the TP53 gene was amplified using the forward primer: 5'-CTCGAG GAACAGCTTTGAGGTG-3' with Xho I sequence in italics and reverse primer: 5'-GGATCC GTCTCTCCCAGGACAGGCACAAAC-3' with the BamHI sequence in italics. PCR amplification was performed at $94^{\circ} \mathrm{C}, 3 \mathrm{~min}$. This was followed by 30 cycles at $94^{\circ} \mathrm{C}, 35 \mathrm{~s} ; 58.7^{\circ} \mathrm{C}, 35 \mathrm{~s}$; and, $68^{\circ} \mathrm{C}, 1.5$ min. Amplified DNA fragments were purified from agarose gel, digested with $\mathrm{Xhol}$ and $\mathrm{BamH}$, ligated into pEGFP-N1 vector (digested with Xhol/BamHI), and transformed into DH5a competent cells. Clones were selected and verified by sequencing. The vector produced was designated as "pEGFP-TP53".

\subsection{Cell culture and transfection}

BGC-823 cells were cultured in an RPMI 1640 medium containing $10 \%$ fetal bovine serum. The cells were transformed with siRNA or pEGFP-TP53 
plasmid using a lipidosome cell transfection kit and following the instructions contained in the user mannual.

\subsection{RNA extraction and reverse transcription}

Cells were harvested and centrifuged. Cell pellets were used for RNA isolation with TRizol reagent by following the instructions contained in the manufacturer's manual. 1 ug of RNA was used for cDNA reverse transcription using a cDNA synthesis kit. Synthesized cDNA was kept at $-20^{\circ} \mathrm{C}$.

\subsection{Western blot}

Total protein was extracted from cultured cells using a protein extraction kit and following the instructions in the manufacturer's manual. Protein concentration was determined by a BCA protein assay. Protein aliquots were kept at $-80^{\circ} \mathrm{C}$. Western blot was performed as described above ${ }^{[13]}$. Forty $\mu \mathrm{g}$ of protein was loaded for each lane and separated on $10 \%$ SDS-PAGE gels. After transferring and blocking, the membranes were incubated with either anti-p53, or $\beta$-actin, antibody overnight at $4^{\circ} \mathrm{C}$. This was followed by a secondary antibody for $1 \mathrm{hr}$ at room temperature. Bands were visualized using $\mathrm{ECl}$ reagents and scanned for density analysis. $\beta$-actin expression was used as an internal control for sample loading.

\subsection{Cell proliferation assay}

Cells in 96-well plates were transfected with siRNA, or plasmid, and continuously incubated for $6 \mathrm{hrs}, 12$ hrs, $24 \mathrm{hrs}$, and $36 \mathrm{hrs}$. Ten $\mu \mathrm{l}$ of CCK8 solution was added to each well and the cells were continuously incubated for $3 \mathrm{hrs}$. Absorbance values were read at $450 \mathrm{~nm}$ in an ultraviolet spectrophotometer.

\subsection{Cell invasion assay}

Invasion assay was conducted in a 24-well Transwell chamber with matrigel-coated membranes. Two hundred ul of $\left(1 \times 10^{5}\right.$ cells $\left./ \mathrm{ml}\right)$ cell suspensions in a serum free medium were spread onto the wells in the upper chamber and 1000 ul of complete cell medium containing $10 \%$ FBS were applied to the wells in the lower chamber. Incubation for 12, 24, and 36 hrs at $37^{\circ} \mathrm{C}, 5 \% \mathrm{CO}_{2}$ followed. Membranes in the lower chamber were removed and stained with $0.1 \%$ crystal violet dye for $15 \mathrm{~min}$. The cells were counted under a Fluorescence Inversion Microscope.

\subsection{The cell migration assay}

Cell migration was analyzed using a wound healing assay. Seeded into 6 -well plates were $5 \times 10^{5}$ cells. After transfection, cells were cultured for $24 \mathrm{~h}$ and then a scratch line was made using pipette tips. After rinsing three times with $1 \times$ PBS, cells were continuously cultured in a serum-free medium for $24 \mathrm{hrs}$. After photographing, scratch width in the photographs was analyzed using Image $\mathrm{J}$ software.

\subsection{Data analysis}

Data were analyzed using SPSS software and presented as mean \pm standard error. Variance Analysis was used for statistical difference. A $p<0.05$ was considered statistically different.

\section{RESULTS}

\subsection{TP53 gene expression in BGC-823 cells}

TP53 siRNA transfection was significantly downregulated (Fig. 1A). pEGFP-TP53 plasmid transfection significantly increased (Fig. 1B) TP53 mRNA expression. pEGFP-TP53 transfection resulted in a $278 \%$ increase in p53 protein expression (Fig. 1C, 1D). TP53 siRNA transfection resulted in a $67 \%$ decrease in p53 protein expression (Fig. 1C, 1D). These findings suggest that the TP53 gene was successfully both silenced and overexpressed 

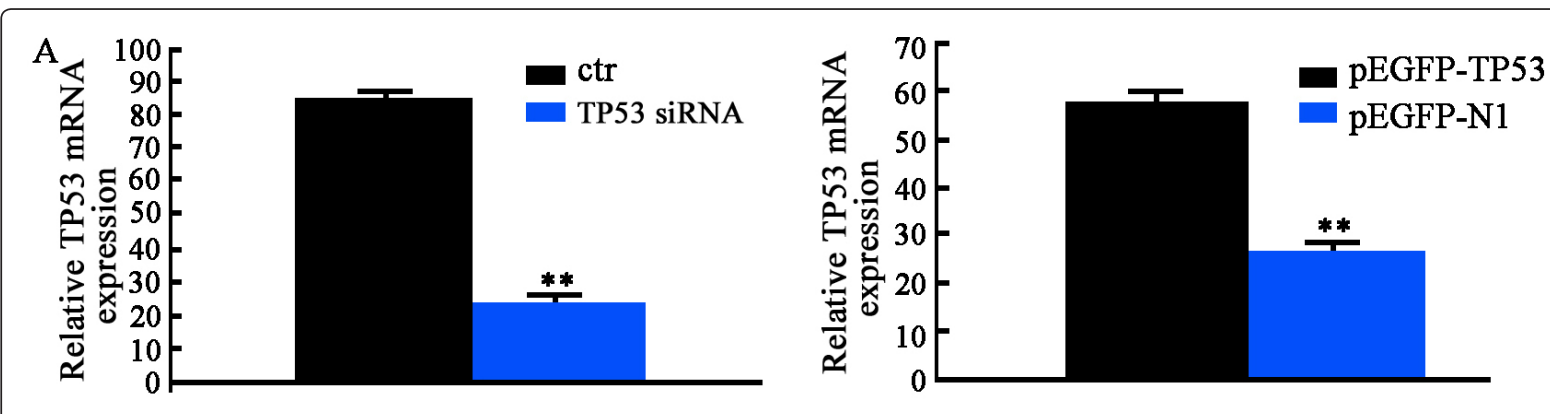

$\mathrm{B}$
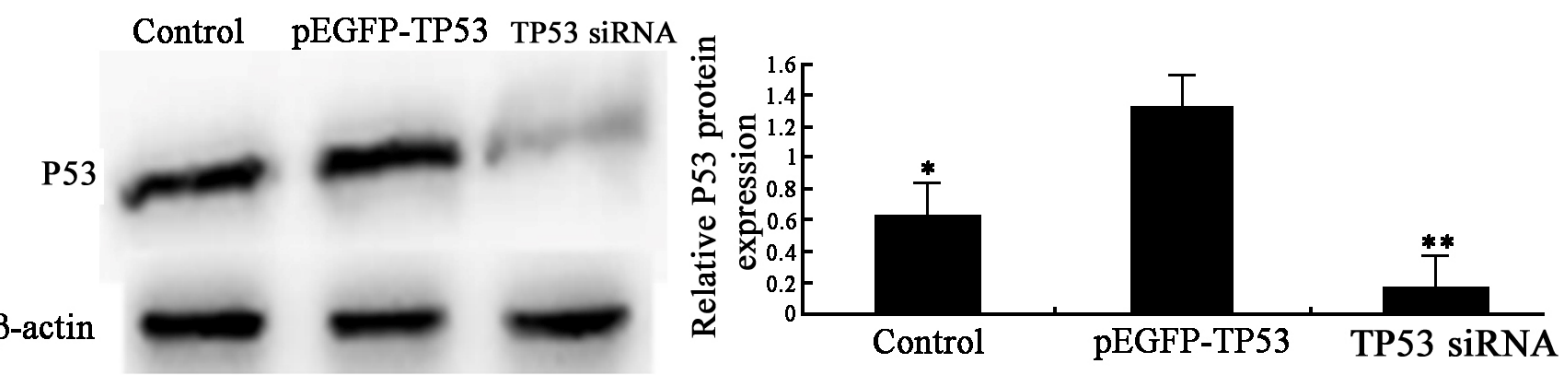

Fig. 1 TP53 gene expression. A) RT-PCR detection of TP53 mRNA expression after transfection of TP53 siRNA (left panel) and pEGFP-TP53 plasmid (right panel). ${ }^{* *} p<0.01$ between two groups. B) Western blot of P53 protein expression. Left panel: representative Western blots. Right panel: semi-quantatitive analysis of Western blots. ${ }^{*} p<0.05,{ }^{* *} p<0.01$ vs. pEGFP-TP53.

Cell proliferation was analyzed using a CCK-8 kit. TP53 siRNA transfection significantly increased proliferation in BGC-823 cells $(p<0.05)$. pGEFP-
TP53 plasmid transfection significantly decreased proliferation in BGC-823 cells $(p<0.05)$ (Fig. 2).

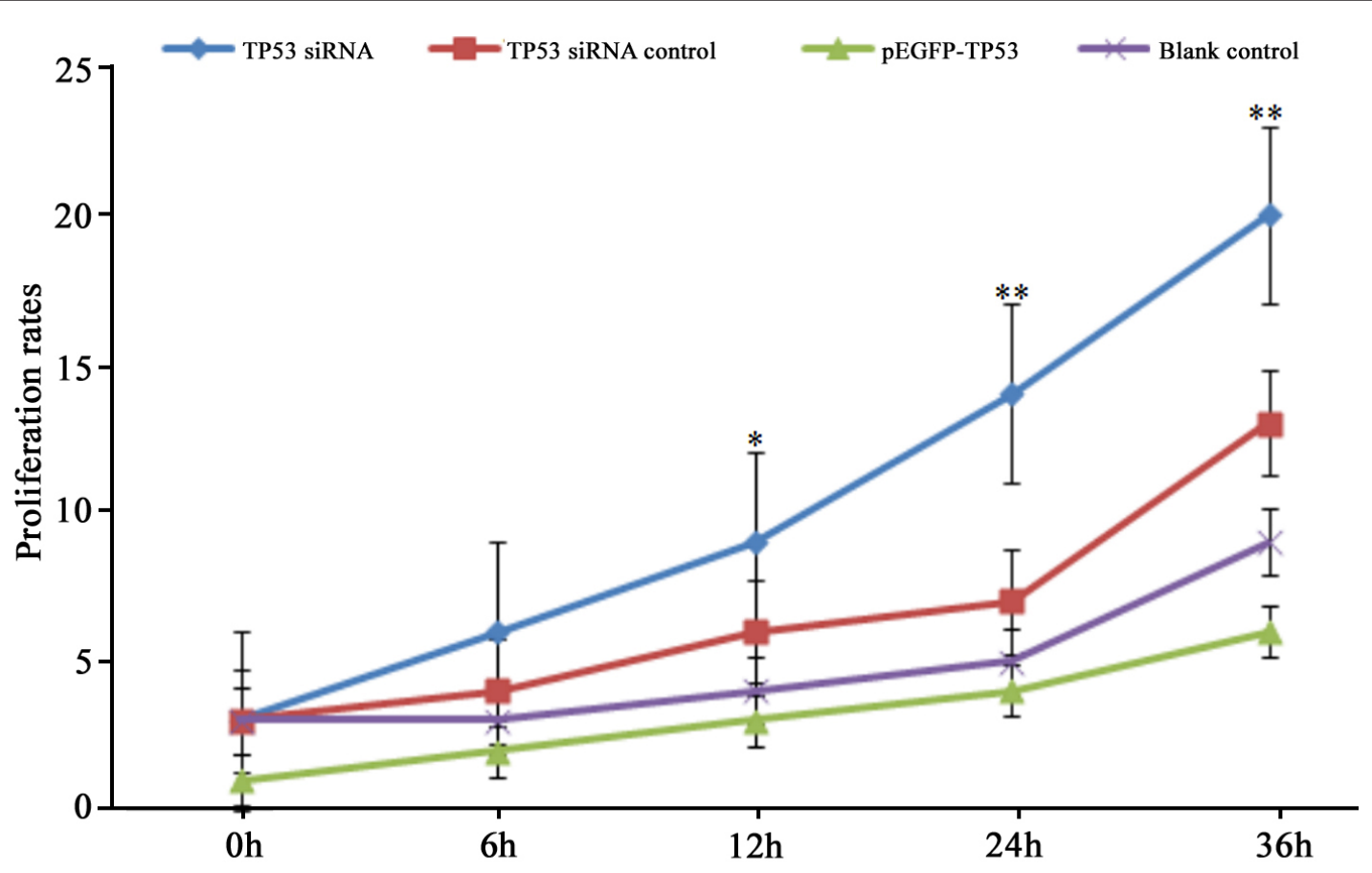

Fig. 2 Cell proliferation rates. Cells were transfected with TP53 siRNA or pEGFP-TP53 plasmid. ${ }^{*} p<0.05,{ }^{* *} p<0.01$ vs. pEGFP-TP53 
A wound-healing assay showed that TP53 SiRNA transfection significantly increased cell migration $(p<0.05)$ and that pGEFP-TP53 plasmid transfection significantly decreased cell migration in BGC-823 cells $(p<0.05)$ (Fig. 3$)$.

\section{TP53 siRNA}

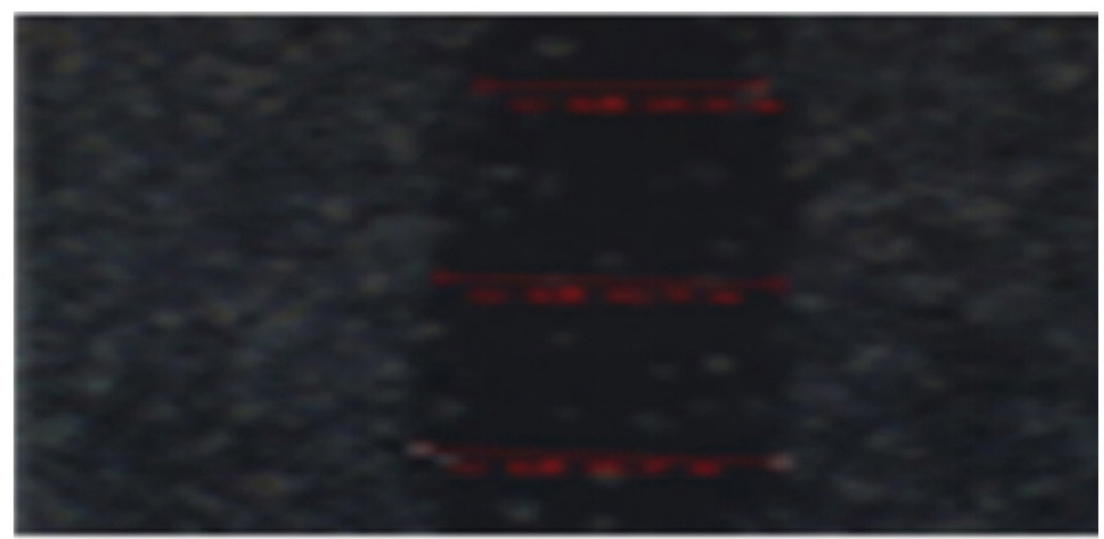

pEGFP-TP53

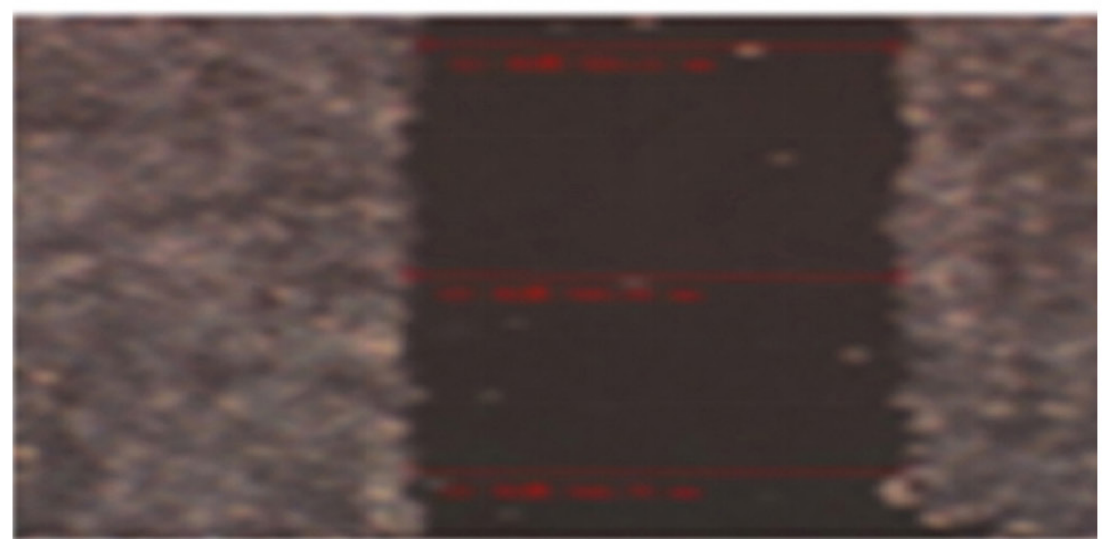

\section{Control}

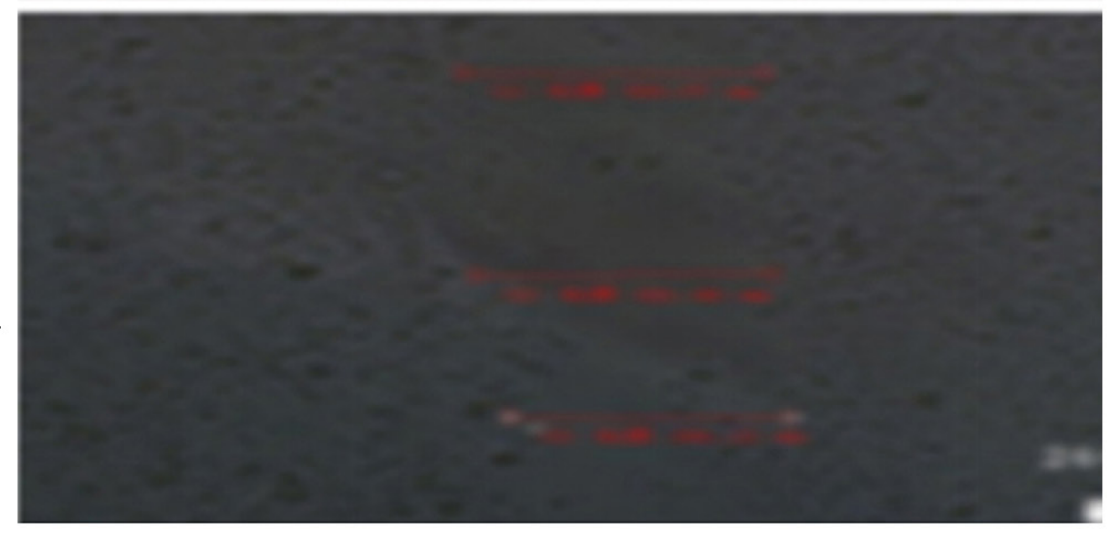

Fig. 3 The effect of p53 on cell migration. Migration was analyzed by wound healing assay.

The Transwell invasion assay showed that TP53 siRNA transfection significantly increased cell invasion $(p<0.05)$, but that pGEFP-TP53 plasmid transfection significantly decreased cell invasion in BGC-823 cells in a time-dependent manner $(p<0.05)$ (Fig. 4). 
A

$12 \mathrm{~h}$

$24 \mathrm{~h}$

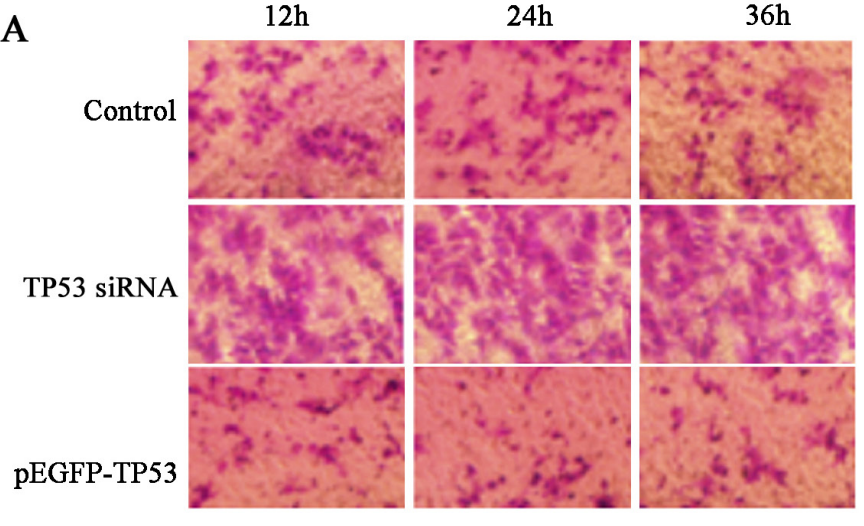

pEGFP-TP53

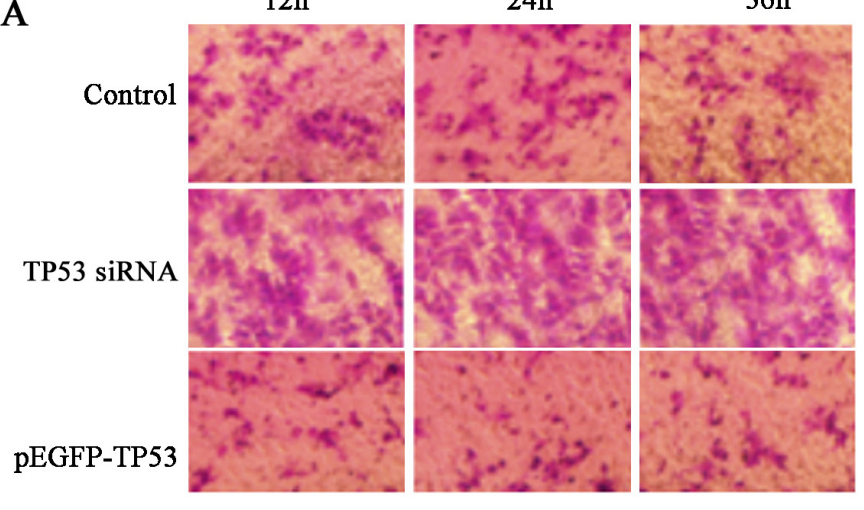

$36 \mathrm{~h}$

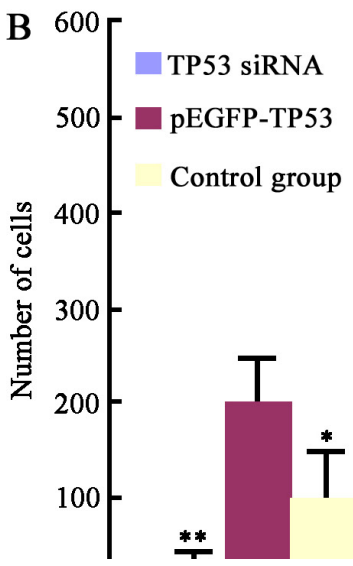

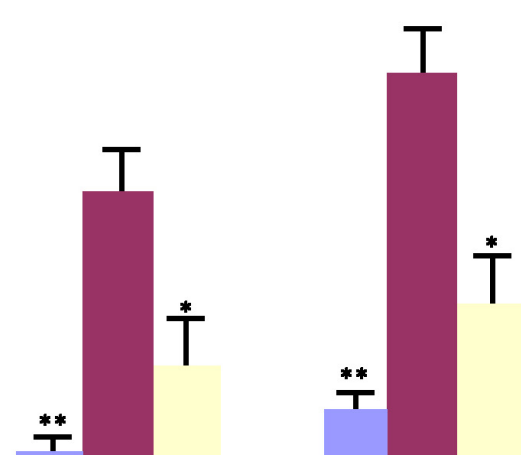

Fig. 4 The effect of p53 on cells invasion. A) Images of transwell champer assay. B) Cell counting of transwell chanper assay. ${ }^{*} p<0.05,{ }^{* *} p<0.01$ vs. TP53 siRNA transfection at the same time point.

\section{DISCUSSION}

Despite an increasing comprehension of molecular mechanisms and the consequent development of targeting therapy for gastric cancers, the prognosis remains poor, particularly in advanced disease patients. TP53 gene mutations have been reported as present in as many as $77 \%$ of metastatic tumor patients ${ }^{[11]}$. These mutations impair p53 tumor suppressor effects, such as inhibiting proliferation, migration, and invasion of gastric cancer cells ${ }^{[12]}$. There is no direct evidence as to whether restoring TP53 gene function could inhibit gastric tumor growth and metastasis. This study detected that silencing of TP53 gene expression significantly increases cell proliferation, invasion, and migration in gastric carcinoma cells, while p53 overexpression significantly inhibits cell proliferation, invasion, and migration.
The functions of the p53 protein includes controlling the cell cycle, inhibiting proliferation, inducing cell apoptosis, stimulating functional factor synthesis, and regulating cell metabolism. It also takes part in DNA damage repair ${ }^{[14]}$. p53 dysfunction is also an important factor driving gastric cancer carcinogenesis and progression. Various types of TP53 gene mutations not only damage its tumor suppressor function, but also produces new functions that promote tumor development and progression. In this study, silencing TP53 gene expression enhanced the malignant phenotype of human gastric adenocarcinoma cells. In contrast, expression of a wild-type p53 protein restored p53 tumor suppressive functions in gastric adenocarcinoma cells. This study indicates that p53 plays a very important role in regulating the proliferation, migration, and invasion 
of gastric carcinoma cells. Restoring TP53 gene expression can restore its p53 tumor suppressive functions and can be used as a treatment strategy.

In conclusion, TP53 overexpression provides an attractive strategy for targetting inhibition of gastric carcinoma cell growth and metastasis.

\section{CONFLICT OF INTERESTS}

The authors declare that they have no conflict of interests.

\section{REFERENCES}

1. Allo $G$, Bernardini $M Q, W u R C$, Shih leM, Kalloger S, Pollett A, Gilks CB, Clarke BA. ARID1A loss correlates with mismatch repair deficiency and intact p53 expression in highgrade endometrial carcinomas. Mod Pathol. 2014; $27:$ 255-261.

2. Bellini MF, Cadamuro AC, Succi M, Proença MA, Silva AE. Alterations of the TP53 gene in gastric and esophageal carcinogenesis. J Biomed Biotechnol. 2012; 2012: 891961.

3. Busuttil RA, Zapparoli GV, Haupt S, Fennell C, Wong SQ, Pang JM, Takeno EA, Mitchell C, Costanzo ND, Fox S, Haupt Y, Dobrovic A, Boussioutas $A$. Role of p53 in the progression of gastric cancer. Oncotarget. 2014; 5: 1201612026.

4. Calcagno $D Q$, Freitas VM, Leal MF, de Souza CR, Demachki S, Montenegro R, Assumpcao PP, Khayat AS, Smith MAC, Santos AKCR, Burbano RB. MYC, FBXW7 and TP53 copy number variation and expression in gastric cancer. BMC Gastroenterol. 2013; 13: 141.

5. Cristescu R, Lee J, Nebozhyn M, Kim KM, Ting JC, Wong SS, Liu J, Yue YG, Wang J, Yu K, Ye XS, Do IG, Liu S, Gong L, Fu J, Jin JG, Choi MG, Sohn TS, Lee JH, Bae JM, Kim ST, Park
SH, Sohn I, Jung SH, Tan P, Chen R, Hardwick J, Kang WK, Ayers M, Dai H, Reinhard C, Loboda A, Kim S, Aggarwal A. Molecular analysis of gastric cancer identifies subtypes associated with distinct clinical outcomes. Nat Med. 2015; 21: 449-456.

6. Thiel A, Ristimäki A. Targeted therapy in gastric cancer. APMIS. 2015; 123: 365-372.

7. Li Y, Liang J, Hou P. Hypermethylation in gastric cancer. Clin Chim Acta. 2015; 448: 124-132.

8. Lee J, van Hummelen P, Go C, Palescandolo E, Jang J, Park HY, Kang SY, Park JO, Kang WK, MacConaill L, Kim KM. High-throughput mutation profiling identifies frequent somatic mutations in advanced gastric adenocarcinoma. PLoS One. 2012; 7: e38892.

9. Mahu C, Purcarea AP, Gheorghe CM, Purcarea MR. Molecular events in gastric carcinogenesis. J Med Life. 2014; 7 : 375-378.

10. Moss SF. Celular markers in the gastric precancerous process. Aliment Pharmacol Ther. 1998; 12: 91-109.

11. Fenoglio-Preiser CM, Wang J, Stemmermann GN, Noffsinger A. TP53 and gastric carcinoma: a review. Hum Mutat. 2003; 21: 258-270.

12. Chen YJ, Wu H, Zhu JM, Li XD, Luo SW, Dong L, Liu TT, Shen XZ. MicroRNA-18a modulates P53 expression by targeting IRF2 in gastric cancer patients. J Gastroenterol Hepatol. 2016; 31(1): 155-163.

13. Zhang $X$, Lee $\mathrm{TH}$, Davidson $\mathrm{C}$, Lazarus $\mathrm{C}$, Wetsel WC, Ellinwood EH. Reversal of cocaineinduced behavioral sensitization and associated phosphorylation of the NR2B and GluR1 subunits of the NMDA and AMPA receptors. Neuropsychopharmacology. 2007; 32: 377-387.

14. Chang VY, Federman N, Martinez-Agosto J, Tatishchev SF, Nelson SF. Whole-exome sequencing of pediatric gastric adenocarcinoma reveals an atypical presentation of $\mathrm{Li}$ Fraumenisyndrome. Pediatr Blood Cancer. 2013; 60: 570-574. 